\title{
Las personalidades psicopáticas y su significación frente a la Ciencia Penal
}

\author{
Por Antonio Pinilla S. C.
}

\section{PARTE PRELIMINAR.}

La Ciencia Penal, y empleamos esta denominación en un sentido amplio de modo que comprenda las investigaciones tanto Criminológicas como Jurídico-Penales basándonos en que ambas coinciden en su objeto material de estudio: el Delito, el Delincuente y la Pena, como toda ciencia, ha ido progresando en el tiempo, se ha acercado cada vez más al conocimiento real de su objeto propio que le permite adecuar cada vez de un modo más objetivo sus medidas prácticas a los fines que pretende.

Pero nosotros queremos insistir en que si bien cabe la evolución y el progreso dentro de la Ciencia Penal, este progreso no debe ir nunca en contra de las bases filosóficas fundamentales que constituyen su esencia misma.

En efecto, cabe, y es vocación fundamental de toda ciencia, el perfeccionamiento metódico. Pero éste no podrá ir nunca en contra de los postulados filosóficos céntricos, que en cuanto evidencias eidéticas, no son susceptibles de evolución o cambio. $Y$ como permanecen inmutables en el tiempo, constituyen los cauces invariables, las trayectorias permanentes, dentro de los cuales, y no en oposición a ellos, es que debe realizarse todo mejoramiento y modernización de métodos.

Es que İa Ciencia Penal, creemos, está profundamente vinculada a la Moral, tiene sus orígenes en ella, y sus postulados conceptuales centrales emanan de ella. Asi el Delito sólo es comprensible como "aquella acción que la CONCIENCIA MORAL de un pueblo (en un momento histórico determinado) juzga merecedora de una pena". La Imputabilidad se basa en la Responsabilidad que sólo se explica si admitimos la Libertad, la propia Autonomía. Y sobre todo, el Valor al que se orienta y cuya realización constituye la razon de ser de la Ciencia Penal, es la Justicia, valor que se concretiza en el mantenimiento intangible del EQUILIBRIO DEI ORDENAMIENTO JURIDICO que exige se le restablezca cuando es perturbado, mediante la imposición de una pena al responsable. 
Son pues los conceptos de la RESFONSABILIDAD en el terreno subjetivo, y de MANTENIMIENTO DEL ORDEN en el objetivo, las piedras angulares sobre las que se asienta la Ciencia Penal. Todo perfeccionamiento metódico debe presuponerlos y no contradecirlos.

Ahora bien, la Escuela Clásica que representó un adelanto para su época ya que insistió en el aspecto objetivo, en la necesidad de juzgar a! delincuente con arreglo a una norma establecida, y no caprichosamente, pecó de teorética pues hizo sus construcciones sobre la base de un hombre ideal (siempre libre y responsable) y no del hombre rea!. De aguí la pena tasada... etc.

La Escuela Positiva reacciona contra este estado de cosas, insiste en el estudio del Delincuente, del hombre real y concreto y en este sentido sienta las bases metodológicas del nuevo Derecho Penal. Pero exageró sus conclusiones científicas y de acuerdo con este error en los hechós, construyó un edifício jurídico falso. Al negar la Libertad, ya que al Delincuente lo conciben como un hombre unívocamente determinado en un sentido por su constitución somato psíquica o por la influencia de factores externos (sociales o físicos), al generalizar precipitadamente sus conclusiones haciendo de todo Delincuente un Irresponsable, derribaron los conceptos de restablecimiento del equilibrio en el Ordenamiento Jurídico, como razón explicativa de la Pena, ya que no habiendo Libertad no cabe orden moral y no existiendo éste no se comprende el ordenamiento Jurídico. Al faltarles asi la base moral de su sistema jurídico, la substituyen por principios utilitarios de Defensa Social, Peligrosidad, Tutela Político-Social etc.

Contra este error científico y jurídico, que se debió en gran parte a querer adecuar las investigaciones científicas a un sistema filosófico positivista forzando asi los hechos en defensa de los principios, ha reaccionado la Nueva Ciencia Penal.

Reconociendo los méritos, apreciables para su época, de los planteamientos metodológicos de la Escuela Positiva, recogemos de ella tan sólo el llamado que nos hizo hacia la comprensión total y concreta del hombre que delinque. Dirección hacia el logro de una mayor justicia en la aplicación de la pena, ya que como dijo Liszt: "la finalidad de la punición no la constituye el delito sino el delincuente; no el concepto, sino el hombre". Pero nos apartamos de su error ideológico fundamental, al que rer adaptar los resultados de su investigación a principios filosóficos ya caducos.

La Nueva Ciencia Penal, una vez disipados del mundo ético, epis. temológico y metafísico los errores positivistas, recurre a sus antiguas bases filosóficas. Negado el determinismo dentro de la Psicología gracias a los análisis fenomenológicos de nuestro psiquismo, especialmente de nues. tras facultades intelectivo-volitivas, el concepto de la Responsabilidad basada en la autodeterminación libre y consciente, resurge más fuerte y vital que nunca. Habiendo hecho quiebra en el mundo ético-axiológico los valores sentimentales y sociológicos del positivismo, los valores cspirituales de Justicia y Orden Jurídico brillan más que nunca en la cumbre de toda escala valorativa.

Por esta razón decimos, la Nueva Ciencia Penal permanece enmarcada dentro de sus tradicionales cauces filosófico-morales y orienta toda su investigación metodológica en razón de los conceptos de IMPUTABI- 
LICMAD basada en la RESPONSABILIDAD y represión justificada por el RESTABLECIMIENTC del Orden Jurídico perturbado. (1)

$\mathrm{Y}$ esta base jurídico-moral se conjuga con la más absoluta estrictez cientifica en sus investigaciones metodológicas. No trata de adecuar los hechos a los principios, tan sólo busca conocer la realidad concreta de ellos. Insistimos sí en el conocimiento del hombre delincuente, pero sin exac.y.: la ampitind de nuestras conclusiones.

Justamente para demostrar los caracteres científicos que han de tencr las investigaciones de la nueva escuela Técnico - Juridica de la Ciencia Penal, es que realizamos la presente investigación.

La Escuela Positiva gracias a Lombroso insistió en el hecho de que el hombre so siempre actúa de un modo libre y consciente, planteando asi la necesidad de las aportaciones de la psicología y de la Psiquiatría para el conociniento cabal de' hombre como sujeto del Derecho Pena!. Al lado del hombie normal existe el hombre anormal. Pero la Psiquiatría como discipina cienfifica estaba recien en sus albores y por esta razón sus exploraciones pecaron de imprecisas y exageradas. Amplió excesivamente el concepto de anormalidad y lo identificó con el de enfermedad. Todo sujeto con aro:malidades se creyó que era un enfermo, y a todo enfermo mental se asoció la idea de irresponsabulidad.

Esto tuvo en el campo jurídico una desastrosa repercusión pues si bien antes se realizaron injusticias condenando a verdaderos entermos, ahora en virtud de disgresiones psiguiátricas mal asimiladas y poco comprendidas, se liberó como a enfermos a una serie de sujetos perfectamente responsables.

Felizmente hoy en día la Psiquiatría como discipina ha cobrado madurez $v$ sus conclusiones científicas más objetividad y estrictez. En efecto, claro está, un gran porcentaje de hombres delincuentes son incapaces - enfermos mentales como lo denotan las últimas estadísticas realizadas (por ejemplo las de Pilcher en los Estados Unidos, las de Olof Kimberg en Suecia, etc), pero al lado de estos sujetos verdaderamente inimputables, existe un gran número, que aunque padezcan de alguna anormalidad, son sujetos por lo general responsables. Es a un grupo de estos sujetos a los que nos vamos a referir en la presente investigación: las PERSONALIDADES PSICOPATICAS.

Su estudio permitirá a los Jueces estar sobre la pista de la verdadera aituación mental de muchos sujetos para los que se invoca la eliminación - atenuación de la pena, basándose especialmente en los artículos 85 inciso $1^{\circ}$ y 90 de nuestro Código Penal. Entonces se podrán atener sus jui cios acerca de la culpabilidad, a un criterio más estricto, cientifico y objetivo. $Y$ al aplicar las penas, que felizmente dada su flexibilidad permiten una mayor justicia en su individualización, podrán adecuarlas del modo más conveniente (en miras al logro en lo posible de la readaptación) a las divereas personalidades de dichos sujetos. Asi como también al aplicar lo

1).--Niestro actual Código Penal responde a esta orientación, ségún se desprende de su articulado y de la Exposición de Motivos en donde leemos: “....el proyecto Suizo considera el delito como un acto consciente y voluntario que infringe la ley... el proyecto peruano ha seguido esta fórmula". 
deja de aplicar las Medidas de Seguridad que, siguiendo el ejemplo del Código Suizo, nuestro actual Código Penal contempla.

Dadas las condiciones de culpabilidad que nuestro Código consigna en la segunda parte del artículo 81 :

a) La conciencia, el conocimiento.

b) La voluntariedad.

Que se resumen en la libre y consciente autodeterminación.

Tanto en la Parte General, como al hacer la descripción de los diversos tipos de Personalidades Psicopáticas, veremos si efectivamente se puede afirmar o no que en estos sujetos el conocimiento y la voluntad se hayan lo necesariamente perturbados, como para producir la irresponsabilidad y por lo tanto la inimputabilidad.

Claro está que sólo tendrán nuestras conclusiones validez como índices, como Tipos promedio y no como criterio absoluto, pues cada persona constituye una individualidad cósmica y originaria, $y$ en cada caso será necesario realizar sobre ellas un estudio comprensivo: concreto $e$ integral.

En consecuencia, este trabajo comprenderá:

Una Parte General en donde estudiaremos de un modo genérico las Personalidades Psicopáticas, para hacer resaỉar desde el punto de vista de la Nueva Ciencia Penal su importancia y significación frente al ordenamiento jurídico de la sociedad, y concluir acerca de su propia autonomía, condición indispensable para determinar de un modo general si estos sujetos son o no IMPUTABLES.

Una Parte Especial en donde estudiaremos de un modo específico las diversas categorías de Personalidades Psicopáticas, dando los caracteres distintivos que faciliten su reconocimiento en la práctica. Y apuntando también a la determinación dentro de cada tipo, de su importancia social y de su grado de responsabilidad.

Una Casuística Local, que aunque imperfectamente realizada dado que no se cuenta con los medios necesarios, servirá como ejemplarización. $Y$ algunos datos Estadísticos. 


\section{PARTE GENERAL}

\section{CAPITULO PRIMERO}

El concepto de Personalidaà.

La Personalidad Anormal.

La Personalidad Psicopática.

EL CONCEPTO DE PERSONALIDAD._Pessina dijo: "El hombre no delinque en cuanto es, sino en cuanto opera". El sentido de esta frase que tiene valor frente a las exageraciones positivistas que negaban la libre actividad del hombre pues lo consideraban condicionado en su actuar de un modo fatal por su constitución somato-psíquica, necesita hoy día una aclaración, pues si bien esto es verdad en tanto que por regla general aceptamos la libre determinación, debemos hacer notar que es un principio evidente el que "la operación sigue al ser" y que por lo tanto todo modo de actuar de un individuo, responde dentro de grandes rasgos al modo de ser de este individuo.

Interesa pues desde el punto de vista de la Ciencia Penal saber algo acerca de estos modos de ser del hombre para hacer más comprensibles sus modos de actuar.

Esto nos lleva al planteamiento de la noción de Personalidad. El concepto vulgar entiende por personalidad " aquel conjunto de notas distintivas de un sujeto ( $y$ que se revelan especialmente en el plano de su conducta), que lo diferencia de los demás".

Hablando con más rigor científico, aunque sin entrar en la discusión filosófica del problema de LA PERSONA, o sea, indicando el concepto psicológico-práctico que la psiquiatría contemporánea acepta, diremos que por Personalidad se entiende: "El conjunto de sentimientos y va. loraciones, de tendencias y voliciones de un hombre". Definición que como vemos se extiende exclusivamente al aspecto OPERANTE y al aspecto ETICO-VALORATIVO del hombre.

Como hipótesis de trabajo, no se incluye dentro del concepto de Personalidad el plano RACIONAL-INTELECTIVO (intuición intelectual, juicio, raciocinio, facilidad de comprensión, pensamiento lógico, memoria, etc) ni el plano INSTINTIVO-VITAL (el conjunto de sentimientos e instintos corpóreos y vitales).

El concepto de Personalidad asi restringido tiene pues en cuenta aquel plano del hombre sobre el cual se interesa de un modo preferente la Ciencia Penal: el plano VOLITIVO-OPERATIVO y el plano ETICO-VALORATIVO.

En efecto, las primeras investigaciones que se hicieron en psiquiatría y que las podríamos considerar como un esbozo de los actuales conceptos de Personalidad Anormal y. Personalidad Psicopática, fueron los que se desarrollaron dentro del concepto de MORAL INSANITY (2) y

2).-Ver J. C. Prichard "A tratise on insanity and other disorders of the mind" (1835). 
que comprendía especialmente el estudio de aquellos hombres EN QUE LOS PRINCIPIOS MORAL Y ACTIVO estaban fuertemente PERVERTIDOS y que por lo tanto su conducta iba en contra de la sociedad. Por ra. zón del estado aún rudimentario de la psiquiatría de aquel entonces y al cual ya nos hemos referido, se incluyó este aspecto del hombre dentro de las ENFERMEDADES MENTALES cometiéndose asi el doble error de confundir las ANORMALIDADES con las ENFERMEDADES y el plano de la PE,RSONALIDAD con el plano RACIONAL INTELECTIVO.

Fué debido a J. L. A. Koch (1888) que se distinguieron de un modo preciso los conceptos de Anormalidad y Enfermedad y ya scbre esta base se delimitó el plano de la Personalidad del hombre en el sentido que hoy se acepta. Koch investigó así las anormalidades de la personalidad, te niendo su aporte como características: De un lado la fuerte $\mathrm{v}$ consciente reacción contra la tendencia, fruto de la Escuela Positiva, a ver enfermos e irresponsables en quienes no lo eran. De otro, el hacer que la psiquiatría contribuyese a asegurar y no a burlar la realización de la justicia.

ANOTACION.-Delimitado el plano del hombre que comprende el concep. to psiquiátrico de Personalidad, indiquemos que dada la especial importancia de este plano (que es por excelencia el plano moral del hombre) con referencia a lo SOCIAL, las características típicas que tengan los SENTIMIENTOS, VALORACIONES, VOLICIONES y TENDENCIAS de un hombre, o sea las características típipicas de su Personalidad, serán a la vez los caracteres por los que los demás hombres individualicen a este sujeto dentro de la vida en scciedad, o sea, frente a los demás.

Vemos pues asi las profundas vinculaciones entre el concepto corriente y el cencepto psiquiátrico de personalidad.

LA PERSONALIDAD ANORMAL. -Una vez definido y delimitado lo que entendemos por la Personalidad y después de haber resaltado la especial importancia que tiene este aspecto del hombre para la Ciencia Penal, examinemos ahora el concepto psiquiátrico de personalidad anormal.

El concepto de personalidad ya lo conocemos.

Para comprender el concepto de anormalidad, tendremos que aclarar el concepto de normalidad.

La normalidad puede entenderse de dos modos diversos:

a) Como el término medio. Criterio Cuantitativo.

b) Como aquello que se adecúa a su finalidad específica. Criterio Cualitativo y Teleológico.

En consecuencia la anormalidad puede entenderse también de dos modos diversos:

a) Lo que se aparte, tanto en sentido positivo como en sentido negativo, del término medio. Criterio Cuantitativo de Kurt Schneicler.

b) Aquello que se desvía de su finalidad específica, de su tipo ideal. Criterio Cualitativo y Teleológico de Honorio Delgado.

A nosotros nos parece más conveniente el criterio cualitativo $\mathrm{y}$ te leológico, dado que en estas consideraciones y más aún desde el punto de vista de la ciencia penal, las apreciaciones valorativas son indispensables. 
Y decimos esto pues con el criterio meramente cuantitativo se cae en el absurdo de ver tanto a un criminal como a un genio o a un santo, en el mismo plano anormal. Esto va en contra del sentido común. Como indica Honorio Delgado la misma sabiduría del lenguaje, la evidencia: la palabra normal, del latín normalis, deriva de norma, palabra que viene del griego y tiene dos significaciones principales: familiar o conocido (por frecuente) y noble o aristócrata. Por lo tanto en sentido estricto un santo o un genio nunca podrá ser en cuanto tal un anormal pues en lugar de apar. tarse, son los seres que estan más cerca del tipo ideal de hombre.

De acuerdo con estas consideraciones, la definición que daremos de Personalidad Anormal será la siguiente:

"Personalidades Anormales son aquellas que suponen desviaciones del Tipo Ideal, más perfecto, de Personalidad Humana".

Pero queremos insistir en que esta discusión no dice nada acerca de si la anormalidad en cuanto tal se pueda identificar con el concepto de enfermedades. Es verdad que los conceptos de anormalidad y enfermedad; coinciden en este parecido': ambos tienen un carácter valioso negativo. Pero sin embargo existe una diferencia radical. Mientras que una Personalidad Anormal, un modo de ser anormal, indica tan sólo ( y en el plano psíquico que comprende la personalidad exclusivamente) una simple desviación del Tipo ldeal, el concepto de enfermedad significa una perturbación o inferioridad grave (que se extiende indistintamente a todos los planos psíquicos del sujeto) y que supone siempre un trastorno corpóreo (orgánico-fisiológico) básico.

ANOTACION.-Insistimos en esta distinción, atendiendo a una necesidad práctica desde el punto de vista Penal, que ya la vislumbró Pelman en 1892 al decir: "Se hace de cada anomalía una enfermedad y de cada individuo extravagante una categoría patológica". "Hemos de tropezar aqui constantemente con conceptos tan imprecisos como el de locura moral o el delirio de los litigantes, co mo si solo litigasen los locos y ningún sano mental pudiese ser un perfecto bribón".

LA PERSOMALIDAD PSICOPATICA - -E! concepto de Personalidad Psicopática sólo es comprensible en función del concepto más amplio de Personalidad Anormal.

De aquí que definamos a las Personaiidades Psicopáticas, como "aquelias Personalidades anormales que sufxen por su anormalidad, o hacen sufrir con ella a la Sociedad". Su característica psiquiátrica lípica consiste en que estos sujetos, a consecuencia de la anomalía de su Personalidaci tienden a llegar en toda situación de importancia vital, a conflictos internos o externas. Entorces los conflictos externos que tengan (conflictos de significación Social) se explican en virtud de los caracteres inmanentes de sus Personalidades, y no como un resultado de la influencia de estos factores externos. Es que como muy acertadamente indica Schneider los factores externos (físico-sociales-educacionales) tienen relativamente poca impor tancia como factor condicionante frente a estos sujetos, dado que el modo de ser psicopático aflora desde la primera infancia y acompaña al sujeto durante tocla su vida. Claro está, éste modo de ser sólo debe entenderse en el sentido de predisposición y nunca como factor condicionante absoluto $\mathrm{y}$ unívoco. 
En este modo de ser psicopático, que surge desde el inicio de la vida del hombre, es indudable que el factor congénito y heredológico tieno una importancia grande. Pero lo dicho no excluye en principio, el que las experiencias vividas, la educación etc. tengan una cierta importancia, ya que toda personalidad se desarrolla y todo desarrollo lo comprendemos como el resultado de la acción determinante, tanto de los factores congénitos, como del cúmulo de lo vivido.

ANOTACION.-Hemos de indicar que la diferenciación, que quiso hacer Koch y que es aceptada por Honorio Delgado, entre las Personalidades Anormales considerando en ellas dos grupos, a saber: Las PERSONALIDADES FSICOPATICAS"' los que perturban a los demás a causa de su anormalidad". Las PERSONALIDADES NEUROPATICAS "los que tan sólo sufren ellos a causa de su anormalidad". Nos parece que si bien puede aceptarse Teoricamente, desde el punto de vistá práctico resulta innecesaria y sería algo dificultosa en su aplicación, pues es muy difícil hacer esta diferenciación como Tipos en cada caso concreto, pues por lo general se presentan ambos caracteres a la vez. Por estas razones preferimos quedarnos con el concepto de Personalidad Psicopática que hemos dado y que comprende ambos caracteres a la vez.

Antes de seguir adelante quiero hacer una pequeña recapitulación insistiendo en lo siguiente:

$\left.1^{\circ}\right)$ Que dentro del concepto de Personalidad no se incluye el plano intelectivo del hombre; luego en principio, al predicar de un sujeto la Personalidad Psicopática no decimos nada acerca del estado intelecitvomiental de dicho sujeto.

$2^{\circ}$ ) Que el concepto de Persanalidad Anormal no supone ningún estado patológico, porque son distintos los conceptos de anormalidad y en. fermedad.

$3^{\circ}$ ) Que el que la Personalidad Psicopática sea algo innato y permanente, no niega en absoluto la libertad, la propia autodeterminación. Pues el tender a "un modo de ser" dado no supone la necesaria determinación en cada caso concreto a actuar de un modo dado.

\section{CAPITULO SEGUNDO}

Caracteres Generales comunes a las Personalidades Psicopáticas

Las Personalidades Psicopáticas y los factores Somáticos:

El problema de las Localizaciones.

El problema de la Complexión Fisíca.

Las Personalidades Psicopáticas y los factores Heredo-Iógicos

Las Personalidades Psicopáticas y los factores Ambientales.

Las Personalidades Psicopáticas y los Estados Psico-Patologicos.

Las Personalidades Psicopáticas y las Psicosis.

Las Personalidades Psicopáticas y las Neurosis. 
Las Personalidades Psicopáticas asi caracterizadas, especificadas y delimitadas frente al problema de la propia AUTONOMIA (determinación libre y consciente).

\section{CARACTERES GENERALES COMUNES A LAS PERSONALI-} DADES PSICOPATICAS.-Aún teniendo en cuenta que el factor indivi. dual y original es diverso en cada sajeto y que por lo tanto exige en cada caso concreto una compresión estructural e integral, sin embargo, creo que podemos señalar algunos caracteres comunes de las Personalidades Psicopáticas, que tienen un cierto valor como índice en la práctica.

Adelantaremos que en el curso de la enumeración descriptiva, se podrá advertir cómo los caracteres aquí enunciados constituyer por lo general una mera exageración o mengua de los rasgos propios del carácter de $l_{s}$ hombres perfectamente normales. Exageración o mengua de rasgos que tienen su especial significación y relevencia en el terreno de la conducta moral, profundamente vinculada a lo socia!, y que por lo tonto interesan de modo preferente a la Ciencia Penal en su estudio del elemento subjetivo, o sea del hombre que perturba el equilibrio del Ordenamiento Jurídico, que, como ya dijimos, tiene sus bases céntricas en el Ordenamiento Moral de la vida en Sociedad.

Estos caracteres comunes son:

$1^{\circ}$ ) Tendencia a la desadaptación respecto a las nomas aue impone la convivencia en Sociedad.

$2^{\circ}$ ) Voiuntad que se dirige más a la satisfacción de as propias ten. dencias y apetitos, que a la sujeción a los principios ético-jutidicos.

39) Dirección hacia la anteposición de los propios cierescs, sobre los legítimos intereses de los demás: Egocentrismo, Sed de Dominación.

49) Inrapacidad para amar (movimiento del ánimo que supone la generosidad y el desinterés pues su nota esencial es la dación absoluta del ser que ama en el amado).

$5^{\circ}$ ) Tendencia a aparentar más de lo que en realidad se es.

En esta descripción, clyas caracteristicas estan perfectamente de acuerdo con la definición dada de Personalidades Psicopáticas, hemos insistido de modo preferente en arjuellos sujetos que "a causa de su anormalidad hacen sufrir a los demás".

$Y$ digo que hemos preferido insistir en este segundo grupo, pues a la Ciencia Penal le interesan los Psicópatas en cuanto que son Perturbadores del Ordenamiento Jurídico-Social. A diferencia de la Psiquiatría que sólo se interesa por estos Perturbadores, en cuanto son Personalidades Psicopáticas.

Esto tan sólo quiere decir que aunque coinciden en este punto la Ciencia Penal y la Psiquiatría en cuanto a su objeto material de estudio, se diversifican según los puntos de visia propios de cada disciplina, o sea. respecto de su objeto formal.

LAS PERSONALIDADES PSICOPATICAS Y LOS FACTORES SOMATICOS: El problema de las relaciones entre las Personalidades Psicopáticas y los factores Somáticos nos lleva indefectiblemente al más amplio problema de las relaciones entre la base corpórea y la personalidad en general (problema de las relaciones entre el cuerpo y el espíritu). 
Aquí tan sólo indicaremos, que hoy en día se ha reconocido la falsedad del aserto de la Escuela Positiva, que pretendía explicar de un modo absoluto y unívocamente tanto una facultad psiquica aislada como la totalidad del psiquismo del sujeto, en función en el primer caso de tal o cual trastorno somático (inferioridad o enfermedad) localizado, en el segundo de su especial complexión somato-morfológica.

Admitiendo en principio la diferencia entitativa entre el cuerpo y el alma y negando toda pretensión la determinación unívoca de lo psíquico, afirmamos en el hombre concreto las mutuas relaciones entre los fenómenos psíquicos y las bases somático-fisiológicas.

El problema de las Localizaciones.-El problema en la actualidad esta planteado en términos completamente diversos a los de la escuela positiva. Se trata de ver tan sólo, respecto a tal estado anímico concreto, cual es la relación existente entre tal base anatomo-fisiológica y tal función psíquica. Si se puede afirmar con bastante probabilidad, que tal perturbación en determinada base somato-fisiológica, lleva consigo la perturbación de tal función psíquica (ej. la facultad de juicio) o de tal aspecto de la personalidad del sujeto (ejm. el plano volitivo).

En lo que respecta a las Personalidades Psicopáticas podemos afirmar de acuerdo con las conclusiones científicas más autorizadas y moderinas, que en la actualidad todavía no se ha podido probar ninguna corre. dación univoca entre tal forma de Personalidad Psicopática y tal perturbación en determinada base somato-fisiológica y que más bien se tiende a diferenciar con estrictez los estados psiquicos que se producen a consecuencia de alguna enfermedad o inferioridad corporal : ejmp. ia encefalitis epidemica, de las genuinas Psicopatías. (Homburger).

Como acertadamente indica Schneider en contra de Kleist y Wernicke, hasta hoy en día podemos afirmar que "no se ha probado nada acerca del asentamiento localizatorio de las Psicopatías".

Esta conclusión de la psiquiatría contemporánea nos permite afirmar ya en el terreno de la Ciencia Penal, que no podrá aceptarse ante los Tribunales, por anti-científico, este argumento:

"Tal Psicópata actuó de este modo puesto que no podía haber actuado de otro, ya que tal modo de ser y de conducirse (tal tipo psico.pático) se debe a tal perturbación (enfermedad o inferioridad) en tal base somato-fisiológica, que lo determina unívoca y necesariamente... luego no siendo libre de autodeterminarse, no puede ser responsable."

Pues científicamente no están probadas las localizaciones de las Psicopatías, o sea, la correlación unívoca entre el trastorno de tal órgano - tal funcionalismo somático y tal modo de ser psicopático.

El problema de la Complexión Física.-Según el principio general enunciado: que comprende al hombre como un todo psicofísico coherente y orgánico, son indudables las mutuas correlaciones entre la complexión física del hombre y sus caracteres espirituales.

Conforme a lo dicho, en la actualidad se plantea el problema desde el punto de vista de las correlaciones, o sea, de los puntos de contacto entre tal complexión y tal modo de ser personal en este hombre concreto, superándose asi las pretensiones apriorísticas de la Escuela Positiva consistentes en ver una determinación necesaria del modo de ser espiritual por el modo de ser físico. Apriorismo que comprende en gran parte todas las 
especulaciones deterministas acerca del criminal nato determinado por su aspecto morfológico.

Pisando sobre este terreno, los datos científicos contemporáneos nos indican que lo más que se puede afirmar es que en el hombre como ser unitario, el destino de su complexión física esta ligado profundamente al destino de su personalidad.

Ahora bien, pero lo que a nosotros nos interesa saber desde el punto de vista de la Ciencia Penal, es: hasta que punto responde la personalidad a los especiales caracteres de la complexión. Planteando los problemas más precisamente:

¿Podría darse un diagnóstico de la Personalidad Psicopática a base de la complexión? o sea.

¿Está univocamente determinada la Personalidad por los caracteres típicos de la constitución?.

Respecto a lo primero, la Psiquiatría actual admite que en lo que respecta al plano temperamental, es indudable la gran influencia de la complexión. Pero que en el plano Caracteriológico, o sea en el plano propio de la Personalidad, la influencia es cada vez menor conforme nos ele. vamos en la jerarquía de las funciones psíquicas.

Respecto a lo segundo, se carecen de conocimientos precisos y positivos que pudieran justificar científicamente dicho diagnóstico o determinación (3).

Por lo tanto hablando como Penalistas, tampoco se puede aceptar el criterio de que la constitución física de un Psicópata determine univocamente un modo de ser y por lo tanto el modo de actuar de su Personalidad, o sea, que no se puede afirmar que este psicópata es así, porque su constitución somática de un modo ineluctable, exige que sea asi; que dicho sujeto actuó de ésa manera anti-social, anti-jurídica, por que su Personalidad estaba determinada necesariamente en este sentido por su especial complexión somática.

LAS PERSONALIDADES PSłCOPATECAS Y LOS FACTORES HEREDOLOGICOS.Dijimos que el modo de ser psicopático era algo que nacía con el sujeto y que solía permanecer a grandes rasgos durante toda su vida.

En efecto, los rasgos que caracterizan tanto a una Personalidad Normal como a una Personalidad Psicopática (aquella que se desvía en sentido negativo del término medio). acompañan de un modo más o menos cons. tante al individuo a lo largo de su existencia y por lo general es poco pro. bable, mejor dicho, es difícil que los factores externos (tanto ambientales físicos, como sociales o educacionales) en cuanto tales, y sin la intervención intencionada (consciente y voluntaria) del propio sujeto, logren in.

3).-Como indica Finley, los datos de la encelografía o mejor dicho de la electroencefalografía deben de tomarse con mucha reserva y evitar las conclusiones apresuradas...." AI presente podemos considerar el electroencefalograma como una medida de ciertos elementos neurofisiclógicos del aspecto biológico del problema de la personalidad... Mide la suma de diversos elementos neurobiclógicos que aún no se pueden distinguir claramente". 
fluir de un modo decisivo en éste su modo de ser. El sujeto nace con tales y cuales predisposiciones y este modo de querer, de apreciar, de valorar, se revela de un modo bastante unívoco en su conducta, al travez del tiempo.

Ahora bien, este modo de ser que tipifica al sujeto y que se revela en sus actos para consigo mismo y para con los demás, responde en un modo bastante apreciable, al modo de ser de sus ancestros. $O$ sea que los carácteres de la personalidad de sus ancestros tienen una vinculación profunda con sus caracteres actuales. Por lo tanto los factores heredológicos en la consideración de las Personalidades Psicopáticas, son importantisimos. Esto lo ha comprobado especialmente Stumpf en sus investigaciones acerca de los gemelos. Y como indica acertadamente Honorio Delgado “aunque todavía queda mucho por precisar, el estudio de los gemelos, ofrece la importante prueba de la concordancia completa de los univitelinos y la discordancia también completa de los divitelinos, como no ocurre ni con las psicosis endógenas".

Pero queremos insistir en que el hecho de que existan disposiciones, predisposiciones heredadas, no niega la íntima posibilidad de actuar de un modo diverso pues como ya lo dijeramos el tender a un modo de ser dado, no supone la necesaria determinación en cada situación concreta a actuar de ese modo..."

Por lo tanto el carácter innato y disposicional de la Personalidad Psicopática en cuanto tal, no dice nada de un modo absoluto en contra de la posibilidad de autodeterminarse por si mismo en el actuar.

\section{LAS PERSONALIDADES PSICOPATICAS Y LOS FACTORES} AMBIENTALES. Como ya lo indicáramos, los factores Externos, la influencia tanto del medio físico como del medio social y cultural (educacional) en cuanto tales, o sea sólo en tanto elementos externos que modifican desde fuera, tienen poca ínfluencia respecto de las Personalidades Psicopáti. cas. Aunque no por esto dejamos de reconocer, como también ya lo dijimos, que dado que toda personalidad se desarrolla, en el curso de este desarrollo influyen al lado de lo disposicional, el cúmulo de las experiencias vividas que slempre tienen concatenación con la naturaleza de los estímulos frente a los cuales reaccionan.

Es que dado que la Personalidad constituye algo asi como una estructura, a travez de la cual se capta el mundo exterior (especialmente el mundo de los valores) y conforme a la cual se reacciona y opera frente a él, dado que esta estructura, este como habitáculo conforme al cual vivencia el hombre, aparece con el sujeto desde que nace y por lo general lo acompaña de un modo permanente durante toda su vida, todos los estímulos e influencias del exterior son aprehendidos conforme a este especial modo de ser estructural, asi como también toda reacción operante estará profundamente concatenada con esta especial estructura de su modo de ser.

ANOTACION.-Es especialmente en el terreno de las Personalidades Psicopáticas ( $y$ hablamos sólo de ellas por no rebasar nuestro campo de investigación, aunque lo que vamos a decir tiene en general validez en otros campos) en donde las exageraciones positivistas que pretendían explicar la conducta del Delincuente como 
un mero producto del Medio (ejmp. Ferri y su ley acerca de la Saturación Criminal) reciben una decisiva refutación científica.

Insistimos en estos puntos, pues, como indica Charles B. Thompson, se ha querido últimamente en los Estados Unidos explicar los diversos Delitos y especialmente la Reincidencia, en función casi exclusiva de los factores externos, ambientales, olvidándose así que en este terreno lo que tiene importancia prominente es el factor congénito: Modo de ser de la Personalidad.

Ahora bien, quiero hacer resaltar que en todo lo dicho nos hemos referido tan sólo a los factores ambientales en cuanto tales y no hemos dicho nada acerca de como son las cosas, en caso de que el sujeto frente a ellos adopte una actitud determinada.

Quiero dejar constancia que en todo lo dicho se ha dejado a salvo la posibilidad de que cada psicópata, en virtud de su intima autonomía, aproveche en tal sentido o en tal oiro los estímulos externos, los deje que 1. influyan, o los rechace.

Es en virtud de esta posibilidad como indica muy bien Klages, que hoy día se aceptan los Tratamientos para lograr mejorar el carácter de estos sujetos (principalmente desplazando de un sector a otro de la vida anímice los síntomas que perturban). Se acepta pues en principio la posibilidad de la Readaptación entre las Personalidades Psicopáticas.

LAS PERSONALIDADES PSICOPATICAS Y LOS ESTADOS PSICOPATOLOGICOS.-Como ya indicaramos, fué a partir de Koch. que ce diferenciaron los conceptos de enfermedad y anormalidad, y en consecuencia entre patología y psicopatía.

Las especulaciones de la Escuela Positiva acerca de las Degeneraciones, constituyeron en este aspecto una fuente de peligros para la verdadera apreciación de lo que son las Personalidades Psicopáticas.

Hoy en día, haciéndose hincapie en el tono eminentemente Caracteriológico de las psicopatías, la psiquiatría no las confunde con los síntomas mórbidos de estados psicopatólogicos tales como la epilepsia, la oligofre. nia etc. que suponen siempre un serio trastorno orgánico ( enfermedad o inferioridad).

Ahora respecto a las relaciones de las Personalidades Psicopáticas con el alcoholismo y la toxicomanía, diremos que aquí no se tráta de ninguna relación fundamental o necesaria. Se trata tan sólo de que debido a la fragilidad de carácter, a la poca fuerza de voluntad que muestran algunos Psicópatas unidos al poco deseo que tienen de corregirse, los lleve en algunos casos (ni más ni menos que como sucede con los hombres normales, si bien en un menor grado) a caer en estos vicios.

Las diferenciaciones establecidas entre las personalidades psicopáticas y los estados psico-patológicos no excluyen el hecho de que en un sujeto concreto se puedan presentar combinaciones (o sea que en una personalidad psicopática se de a la vez por ejemplo la Oligofrenía, o síntomas epiSépticos etc.)

Desde el punto de vista de la Ciencia Penal, interesan especialmente las COMBINACIONES con la Oligofrenia, ya que en estos casos, debido a la escasa inteligencia, la posibilidad de la propia autodeterminación consciente disminuye grandemente $y$ en consecuencia los sintomas psicopáticos 
Be agravan. La posibilidad de la Readaptación también disminuye, y el sujeto se hace más perturbador.

PERSONALIDAD PSICOPATICA Y PSICOSIS.-La Psicosis es una SERIA PERTURBACION ANIMICA que es endógenamente comprensible, - sea, QUE SUPONE UN BASICO TRASTORNO SOMATICO-FISIOLOGICO. Psicosis son la esquizofrenia, la ciclotimia (o locura maniaco-depresiva.). Las Psicosis comprenden pues decisivas perturbaciones de la vida psiquica en general, debidas a profundos trastornos orgánicos.

Vamos a determinar en primer lugar las vinculaciones entre las psicosis y las personalidades psicopáticas y luego sus diferencias.

Es un hecho, que algunos psicópatas presentan algunas veces rasgos farecidos a los de individuos psicóticos; ej. un psicópata anancástico con un psicótico esquizofrenico, un psicópata hipertímico explosivo, con un psicótico ciclotímico...

Esta mera coincidencia llevó a Kretchmer a sostener que había una diferencia meramente gradual entre las personalidades psicopáticas y las psîcosis, y así afirmó la existencia de TRANSICIONES entre unas y otras basándose en parte en que ambas perturbaciones se daban en sujetos con parecida complexión física.

Afirmó pues que existía una escala sĭn limites precisos que iba del individuo normal Esquizotímico al psicópata Esquizoide y de éste al psicótico Esquizofrénico (todos sobre la base de una complexión somática Asténica) y otra que llevaba del individuo normal ciclotímico al psicópata Cicloide y de aquí al psicótico con Loclira Maniaco-Depresiva (todos sobie la base de una complexión somática pícnica).

Sin embargo, esta Aseveración peca de exagerada pues no se conoce positivamente el proceso corporal que existe en el fondo de la esquizofrenia o de la ciclotimia, ni tampoco se sabe nada a ciencia cierta, acerca de las constituciones corporales que sirven de base a las personalidades psicopáticas. Indicando además que en principio una Complexión Física determinada, es quizás una condición de la enfermedad, pero nada más.

Y de hecho, como anota Schneider... "sobre la base de la simple experiencia clínica, hemos de confesar que no encontramos tales Transiciones". Por lo tanto hemos de insistir en la diferencia existente entre las Personalidades Psicopáticas y los Procesos Psicóticos, yendo así en contra de aquellos que quieren ver en las Psicopatías, tan sólo un zrado menor de psicosis, ya que aún en los casos de duda, como indica Schneider... "hay que optar por la negativa en la cuestión de los Estados Limítrofes".

Las diferencias entre la Personalidad Psicopática y las Psicosis, son pues esenciales.

En primer lugar el concepto de Psicopatía no supone necesariamente una perturbación orgánica localizada.

Por otro lado el concepto de Personalidad sólo se refiere al plano caracteriológico (operativo-volitivo, ético-valorativo); el plano intelectivo queda fuera de su compresión. Mientras que en las Psicosis, por ejemplo la esquizofrenia, se extiende a los diversos planos del psiquismo del sujeto, y en el caso particular que hemos señalado preferentemente al plano de la Inteligencia.

Respecto al Diagnóstico Diferencial hemos de decir, que respecto de la Ciclotimia presenta menos dificultades, pues se trata de estados fí- 
sicos, episódicos (y recordemos que la Personalidad Psicopática es un modo de ser más o menos permanente). Respecto do la esquizofrenia presenta más dificultades, pero nunca es imposible.

Todo lo dicho tiene una especial importancia en el campo Penal, pues significa el que se debe ser muy estricto en la diferenciación entre un psicópata y un individuo psicótico respecto de la imputabilidad. $Y$ que conforme a lo dicho respecto a las transiciones, se deben siempre mirar con muchas reservas aquellas argumentaciones en que la defensa alegando que se trata de un sujeto esquizoide (afirmación que supone como cierta las Transiciones) o cicloide, pretenda explicar sus acciones dentro de estados tales como la esquizofrenia o la ciclotimia, procesos que indudablemente, dada la gravísima perturbación de todos los planos del psiquismo del sujeto (en especial el intelectual) que suponen, quitan casi por completo toda res. ponsabilidad. Ya que como hemos visto, existen diferenciaciones esenciales entre las Personalidades Psicopáticas y las Psicosis.

PERSONALIDAD PSICOPATICA Y NEUROSIS._El término neurosis, por desgracia equivoco, hizo que se creyese que las neurosis eran trastormos nerviosos (de la base somático - fisiológica). Afortunadamente la Psiquiatría actual ha determinado de modo preciso que las neurosis son algo exclusivamente psíquico.

En efecto las neurosis son simples reacciones anormales a vivencias, o sea perturbaciones psíquicas exógenamente comprensibles, es decir, originadas por vivencias de determinadas situaciones o conflictos (que generalmente se refieren al mundo externo, aunque también pueden referirse a conflictos internos, del propio psiquismo del sujeto) (4) siológico.

No suponen pues necesariamente ningún trastorno somático fi-

Son siempre comprensibles en función de un acontecimiento vivido. El elemento externo, ambiental, los estímulos, tienen pues una gran importancia en el campo de la neurosis.

Se extienden estas perturbaciones, indistintamente a todos los planos del psiquismo del sujeto (plano afectivo, intelectivo, volitivo).

Una vez aclarado el concepto de neurosis, determinemos en primer lugar sus vinculaciones y luego sus diferencias con las Personalidades Psicopáticas.

Respecto a las vinculaciones tan sólo hemos de decir que de hecho existen caracteres parecidos entre determinados modos de ser psicopáticos y determinadas neurosis; ejmp. entre los Psicópatas Inseguros de si mismo (anancásticos) y los neuróticos obsesivos.

En el fondo de este asunto, lo que hay es que dado que la Personalidad en una tendencia a un modo de ser y por lo tanto de reaccionar, y las neurosis son específicas reacciones anormales a vivencias, ciertas personalidades y en especial las personalidades Psicopáticas, están por su especial naturaleza más predispuestas a que les acometa ante determinado conflicto, una neurosis.

ANOTACION.-Por razón de estas vinculaciones, en la Parte Especial, mientras podamos hacerlo sin violentar los hechos, referi-

4)...Entendemos Exógeno, en el sentido de la oposición Sujeto, Objeto, acto y contenido del acto. 
remos el mayor número posible de casos en que se den COMBINACIONES de Neurosis con determinadas P'ersonalidades Psicopáticas, para comprender así a éstas, orgánica y sistemáticamente, dentro de las estructuras integrales de la Personalidad.

Después de lo que llevamos dicho, las diferencias saltan a la vista:

Mientras que la Neurosis es una perturbación seria que se extiende a los diversos planos del psiquismo (incluyendo la inteligencia), la Personalidad Psicopática es tan sólo una desviación del modo de ser normal más perfecto, y que se extiende exclusivamente al plano operativo volitivo y ético-valorativo.

Mientras que la neurosis es una perturbación en el vivenciar que sobreviene a raíz de un acontecimiento por lo general externo, la Personalidad Psicopática es un modo de ser más o menos permanente, que está profundamente vinculado a las condiciones genéticas, internas; y en las que lo externo tiene una importancia secundaria.

De aquí que Honorio Delgado, refiriéndose a aquellos que dan una importancia exagerada, por decisiva, a los factores ambientales comprendiendo las psicopatías como verdaderas "neurosis del carácter", diga que este extremo, cuando no es puramente especulativo, se funda en consideraciones hechas, no sobre verdaderas personalidades psicopáticas, sino sobire pseudo - psicopatías, de aquí el por qué de su error.

Todo lo aquí indicado tiene especial importancia para la Ciencia Penal, pues conviene que se distingan las neurosis, que por ser serias perturbaciones que se extienden a los diversos planos psíquicos del sujeto (incluso la Inteligencia) pueden atenuar de hecho la responsabilidad, y las Persomalidades Psicopáticas en cuanto que indican meras predisposiciones a estos conflictos, y que por lo tanto exigen el que se pruebe en cada caso si se originó o no el estado neurótico, que de suyo es algo diverso de la mera psicopatía. No explicando asi por principio, el modo de ser de un psicópata como el modo de ser de un neurótico.

LAS PERSONALIDADES PSICOPATICAS ASI CARACTERIZADAS, ESPECIFICADAS Y DELIMITADAS, FRENTE AL PROBLEMA DE LA PROPIA AUTONOMIA (DETERMINACION LIBRE Y CONSCIENTE).

Todo lo que hemos precisado a lo largo de éste capítulo, ha estado orientado hacia el planteamiento de éste problema.

Intencionadamente hemos dejado para el último, el estudio del factor espiritual-volitivo, pues queríamos plantear y discutir las anteriores problemáticas ateniéndonos estrictamente a los hechos y sin recurrir a factores explicativos de otra índole que rebasasen de suyo la esfera de dichas cuestiones.

Pero dado que estabamos estudiando Integralmente, si bien desde un punto de vista genérico, a las Personalidades Ṕsicopáticas, no podemos dejar de considerar un factor esencial tanto para toda psicología científica, como para toda Antropología filosófica: La fuerza original del Espíritu.

En el hombre en general, se ha comprobado fenomenológicamente, que el propio sujeto es el forjador de su destino. De él depende en último 
término la Actitud fundamental, que en cuanto Totalidad, tome su persona frente al mundo (Especialmente fiente al munclo ético. Campo de la conducta).

Por esta razón afirmamos en principio, dado que es un hecho, LA EXISTENCIA DE LA LIBRE Y CONSCIENTE AUTODETERMINACION. Frente a las exigencias vitales y ambientales, frente al tender de nuestras predisposiciones innatas, puede el espíritu del hombre en principio, someterlos y encauzarlas mediante su Voluntad, a las normas de convinencia gue capta mediante su Inteligencia.

Esto ya lo vió el propio Tomás de Aquino al decirnos:

"La elección del espíritu es infiuida por los seritinientos que pro ceden del Apetito Sensitivo. Pero este es disposición corporal y está determinado por la complexión. Pero de exto no nace una necesidad para la elección; está en el poder del espiritu aceptar o rechazar los sentimientos originados". (Q.d.De Veritatae. q 24. a 1, ad. 19).

$Y$ nos lo confirma en la actualidad el gran antropólogo Max Scheler al afirmar: "El hombre es el ser vivo que puede adoptar una conducta ascética frente a la vida-vida que lo estremece con violencia. El hombre puede reprimir y someter los propios impulsos; puede rehusarles el pábulo de las imágenes perceptivas y de las representaciones. Comparado con el animal que siempre dice "si" a la realidad, incluso cuando la teme y rehuye, el hombre es el ser que sabe decir "no", el asceta de la vida, el eterno protestante contra toda mera realidad, el ser nunca satisfecho de la realidad circundante, siempre avido de romper los límites de su ser ahora, aquí y de este modo, de su "medio" y de su propia realidad actual. Y sólo porque es esto, puede el hombre edificar sobre el mundo de su percepción, el reino ideal del pensamiento; y de otra parte, puede canalizar la energía -latente en los impulsos reprimidos - hacía el espíritu que habita en él. Esto es: El hombre puede sublimar la energía de sus impulsos en actividades espirituales". (EL PUESTO DEL HOMBRE EN EL KOSMOS).

Esta Fuerza Original, libre y consciente, del Espíritu hace que rechazemos toda explicación determinista que considere al hombre como un paralelogramo de fuerzas tanto congénitas como ambientales, que expliquen su conducta conforme a las reglas estrictas de la causalidad.

No, la Propia Iniciativa, la propia Autodeterminación Libre y Consciente, existe siempre en todo caso, a no ser que la facultad Intelectivo-Volitiva estuviese anulada por acción de una gravísima inferioridad congénita, de un estado psicopatológico, de una psicosis o de una neurosis grave, que comprometiesen y anulasen esta esfera del espíritu.

SOLO EN ESTOS CASOS, SE PODRIA ADMITIR EN PRINCIPIO QUE ESTABA NEGADA LA POSIBILIDAD DE LA AUTO-DETERMINACION LIBRE Y CONSCIENTE. copáticas.

Veamos ahora el problema en el caso de las Personalidades Psi-

El análisis que hemos realizado en páginas anteriores, nos ha llevado a concluir en los siguientes hechos:

1) Las Personalidades Psicopáticas consisten en la mera acentuación en sentido negativo, de los rasgos del carácter normal, y se extienden 
exclusivamente a determinados planos del psiquismo del sujeto; no com prendiendo en principio la Inteligencia.

$2^{\circ}$ ) Los factores somáticos en relación con las Personalidades Psicopáticas, tanto aisladamente (problema de las localizaciones) como integralmente (problema de la complexión física), son insuficientes para determinar unívocamente la actividad de los sujetos y negar ası la posibilidad de la libre elección.

$\left.3^{\circ}\right)$ Los factores heredológicos, actúan a modo de Predisposición, tendencia en general hacia tal modo de ser, pero no niegan en principio la posibilidad de la libre elección (tan sólo la podrán hacer más difícil) ya que el tender a un modo de ser dado, no habiendo negado la posibilidad de la auto-determinación ya que no negamos en absoluto la facultad intelectivovolitiva, no implica el que en tal caso concreto necesariamente se tenga que actuar de ese modo. (esto tiene validez tanto para las Personalidades Psicopáticas, como para el hombre normal).

$4^{\circ}$ ) Los factores Ambientales, en este caso especialmente, no actúan sino como un mero factor, supeditado a la actitud, fruto de una determinación libre y consciente, que el sujeto tome frente a ellos.

$5^{\circ}$ ) Los estados Psico-patológicos, las Psicosis y las Neurosis, estados en los que cabe la anulación de la facultad intelectivo-volitiva y por lo tanto de la auto-determinación, son en cuanto tales distintos de las Psicopatías. Y la diferencia no es meramente gradual, sino esencial.

POR LO TANTO PODEMOS CONCLUIR DE MODO GENERAL QUE EN UNA PERSONALIDAD PSLCOPATICA EN CUANTO TAL, NO ESTA NEGADA LA POSIBILIDAD DE LA AUTODETERMINACION LIBRE Y CONSCIENTE.

O sea, que el Psicópata en principio no tiene negada su propia Autonomía. Quizás diversos factores (heredológicos, somáticos, ambientales) contribuyan a hacerle más difícil el actuar de acuerdo con las reglas éticojurídicas que rigen la convivencia social, pero siempre le queda la posibilidad de conformar a ellas su conducta, pues su Iniciativa no está negada ya que no lo está la fuerza original de su espíritu comó inteligencia y voluntad.

Prueba fáctica de lo dicho ( y que por supuesto tiene sólo validez como principio general, susceptible claro está de excepciones en la práctica, especialmente cuando se presentan combinaciones con estados psico-patológicos, psicosis, etc.) es el hecho de que en las mismas condiciones, unos psicópatas se determinan a actuar en un sentido negativo frente a la Sociedad, mientras que otros se reprimen, se auto-educan y pueden convertirse en ciudadanos eficientes y honorables, de alto valor social.

Como concluye Honorio Delgado, la actitud, libre y conscientemente determinada, que tome el Psicópata frente a su psicopatía, a su tendencia a ese modo de ser que resulta anti-social, tiene una influencia decisiva. Puede o dejarse llevar... o actuar en el sentido de su propio perfeccionamiento. Alternativa que se da tanto respecto de los psicópatas como respecto de todos los hombres en general. Posibilidad de alternativa que es el fundamento esencial de la Imputabilidad. 